\title{
Towards a Cognitive Cultural Approach to Public Management Reform
}

\author{
Sijko Wierenga (corresponding author) \\ Researcher at the Department of Culture, Organisation and Management at VU \\ University of Amsterdam, De Boelelaan 1081, 1081 HV Amsterdam, the Netherlands \\ E-mail: secretariaat.org.fsw@vu.nl
}

Frans Kamsteeg

Associate professor at the Department of Culture, Organisation and Management at VU University of Amsterdam, De Boelelaan 1081, 1081 HV Amsterdam, the Netherlands

E-mail: secretariaat.org.fsw@vu.nl

Received: Dec. 4, 2017 Accepted: Jan. 2, 2018 Online published: Jan. 8, 2018

doi:10.5296/jpag.v8i1.12227ＵRL: https://doi.org/10.5296/jpag.v8i1.12227

\begin{abstract}
This paper tries to give a preliminary theoretical and methodological answer to a rather complex question: how can we explain the diffusion of an organizational change initiative, inspired by New Public Management (NPM) against the background of the organizational context in which it is supposed to be implemented? The need of such an answer is demonstrated by an analysis of 281 NPM studies, which shows that NPM researchers often produce only abstract or fragmented analyses of the content of both context and change initiatives, and hardly address the question what exactly is to be changed in reality. Our argument is that we should develop an approach that starts from the workplace reality as interpreted by the organizational actors, which may help to fundamentally rethink the way in which NPM initiatives can be implemented successfully. To this end, we present a Cognitive Cultural (CC) approach. We show what results can be obtained by means of a CC research method, by presenting the main conclusions of two NPM case studies taken from the field of education. We then discuss how the $\mathrm{CC}$ approach yields substantial and reliable information for assessing the cognitive relevance of NPM reforms and their underlying elements. Finally, we shall give some suggestions how further research into NPM can benefit from the CC approach.
\end{abstract}

Keywords: new public management, organizational context, cognitive anthropology, 
organizational change, public management reform

\section{Introduction}

Public management reform has been described as "one of the most striking international trends in public administration" (Hood, 1991, p. 3). Osborne and Gaebler's book Reinventing government (1992) is generally seen as the starting point of thinking about organizing public bodies improved in a more business-like manner. In this debate, NPM is one of the leading ideologies. One of its well-known researchers, Christopher Pollitt, summarizes the key elements of NPM (2003, pp. 27-28) as follows: "A focus on outputs and outcomes, a shift towards more measurement and quantification, a preference for lean and mean organizational forms, a preference for contract-like relationships, deployment of market mechanisms, an emphasis on service quality, blurring frontiers between the public and the private sector, and a shift towards efficiency and individualism."

According to Aristigueta and Van Dooren (2007), the improved performance at the heart of NPM-reform is: better products and services for citizens, more control for politicians, more freedom for public managers, or a combination of these. Pollitt and Bouckaert (2017, p. 2) define NPM reform as: "Deliberate attempts to change the structures, processes and/or cultures of public sector organizations with the objective of getting them (in some sense) to run better".

There is some evidence that NPM-reform has led to public organizations acting more effectively and efficiently (Pollitt \& Dan, 2013). But there is also evidence that many NPM-reform initiatives have not been successful, and it is often hard to decide why they failed. Consequently, there is no such thing as best practice for NPM-reform. Pollitt and Dan (2013) argue: "our database holds a good deal of interesting information about changes in output resulting from performance-oriented reform, but what the collectivity of this knowledge suggests, is that these vary enormously, from highly positive through 'no change' to rather negative, depending on circumstances" (p. 20).

In line with Pollitt and Dan (2013), and Pawson (2013) we argue that, in order to improve the chances of attaining the goals of improved performance, we need a generally applicable, explanatory and context sensitive model for the diffusion of a particular change initiative in a particular context. The key question of this position paper is therefore:

How can the diffusion of specific NPM-inspired change initiatives be explained in relation to the organizational context in which they are to be implemented?

In this paper three successive steps are taken. First, we demonstrate that NPM scholars have difficulty in answering this question. On the basis of an analysis of a sample of 281 of their papers, we conclude that this may be caused by a rather abstract or fragmented approach to both the content of change and the particular context. Secondly, we present our newly developed cognitive-cultural (CC) approach, the CC-framework, as a solution to the constant discomfort about the relation between change and context. The idea is that this framework focuses on the crucial link between the content of a particular change initiative and the context in which it is supposed to be implemented. We argue that an effort to fundamentally 
rethink NPM implementation strategies does not have to be built from scratch, because we can build on robust cognitive anthropological work, in particular Dan Sperber's Explaining culture: a naturalistic approach (1996). In the third place, we will present the research method that is inferred from this framework and we will highlight its usefulness in two NPM case studies. In the final section, there is the discussion how the $\mathrm{CC}$-framework provides valuable information for assessing the overall relevance of particular NPM-reforms and their underlying elements. We also give some suggestions on how some of the studies that we reviewed in the first section may benefit from this alternative approach and how the CC-framework can be applied in the study of macro and micro level NPM reforms.

\section{NPM and Context, a Difficult Relationship}

In his evaluation of NPM inspired organizational change, Pollitt stresses the "need for a careful analysis of the specific activities, the goals which are set for the particular reform, and the context in which it is to take place" (Pollitt, 2003, p. 49). In fact, we feel that such an analysis is a sine qua non for concluding in specific situations to what extent the benefits of public management reform are realized and how its disadvantages can be overcome. The question we asked was to what extent and how thoroughly Pollitt's analysis, quoted above, is actually carried out in empirical studies. Finding an answer to this meant sifting scientific publications of public management reform published twelve months after Pollitt's advice appeared or later. We took a sample of the publications by selecting articles that refer to Hood and Peters' article "The middle aging of new public management: into the age of paradox?" (2004). This sampling strategy seemed appropriate, because Hood and Peters - two widely recognized scientific NPM experts- published their article soon after Pollitt's (2003) advice. We also considered that this sample would provide a valid picture of the whole range of investigations into NPM change initiatives, more so than a possible alternative, purposive sampling, which would have meant choosing only the well-known names in the current NPM debate. We used Scopus, the largest abstract and citation database of peer-reviewed literature, to take the sample, a selection method that is not unusual (Chirici, 2012; Fekete, Siegrist, \& Tough, 2017; Zyoud, Al-Jabi, Sweileh, \& Awang, 2014). We took a first sample on 5 July 2015, resulting in 228 articles, and a second sample on 12 July 2016, resulting in 281 articles. The increase of the number of articles may be indicative that Hood and Peters' (2004) article is still relevant.

From the 281 articles, we then selected only those articles that report on case studies of NPM-inspired changes, since Pollitt emphasizes the investigation of specific cases of change in specific contexts. Seventeen percent of the selected articles, that is 49, appeared to do this, as we concluded from their methods sections. At this stage, we did not yet make an additional selection based on a pre-given definition of context; we just tried to infer how the authors conceptualize and analyse context, implicitly or explicitly. 
Table 1. Quantitative empirical studies referencing Hood and Peters (2004)

\begin{tabular}{lc}
\hline Article reference & Method of data collection \\
\hline Adams, Muir, and Hoque (2014) & Ques \\
McDavid and Huse (2012) & Ques \\
Park and Joaquin (2012) & Ques \\
Shin (2010) & Ques \\
Shin and Jung (2013) & Ques \\
Steyvers, Reynart, De Ceuninck, and Valcke (2006) & Ques \\
Steyvers, Reynart, and Block (2010) & Ques \\
Tummers and Den Dulk (2013) & Ques \\
Verbeeten (2011) & Ques \\
Verbeeten (2008) & Ques \\
Vigoda-Gadot, Eldor, and Schohat (2012) & Ques \\
Willem and Buelens (2007) & Ques \\
Zafra-Gomez, Rodriguez Bolivar, and Alcaide Munoz (2012) & Da \\
\hline
\end{tabular}

Note: Da = Document analysis

Ques $=$ Questionnaire

In the selected studies, we then checked if - and to what extent - the context is described. We also checked to what extent the NPM-inspired change content is described, as we believe that the content of the change should also define the scope within which the context should be investigated.

The above analysis revealed that 13 articles use a quantitative research method (Table 1). These studies focus, for instance, on measuring effects of NPM interventions on job satisfaction (Shin \& Jung, 2014), on measuring performance reporting expectations (McDavid \& Huse, 2012), seeking opinions about NPM-inspired interventions (Steyvers et al., 2010) or investigating the relationship between NPM-caused work alienation and organizational commitment (Tummers \& Den Dulk, 2013).

From these 13 articles, 4 studies actually try to define both the change content and the organizational context: Verbeeten (2008), Shin (2010), Willem and Buelens (2007) and Zafra-Gomez et al. (2012). Only Willem and Buelens (2007) operationalize context in a concrete manner, using a substantial number of pre-existing and validated scales, as well as some newly-defined scales. They investigate correlations between level of knowledge sharing and contextual factors, such as level of trust, identification and power games. Unfortunately, the authors seem to have felt no need to define and conceptualize context properly, and their choice of contextual aspects seems rather opportunist, resulting in only a fragmented view of the context. As a result, it cannot be shown whether there are other, perhaps more important, contextual factors that correlate with knowledge sharing. Neither can it be established to what extent the context as such relates to knowledge sharing. The three other studies operationalize context with a limited number of items, which are formulated in rather abstract terms.

Subsequently, we examined the 31 qualitative and five mixed method studies (see Tables 2 and 3), which are all (multiple) case studies. Again, we analysed the way in which both change content and context are operationalized. 


\section{Macrothink}

Journal of Public Administration and Governance

ISSN 2161-7104

2018, Vol. 8, No. 1

Table 2. Qualitative empirical studies referencing Hood and Peters (2004)

\begin{tabular}{lc}
\hline Article reference & Method of data collection \\
\hline Almqvist, Catasús, and Skoog (2011) & $\mathrm{Da} / \mathrm{Int}$ \\
Anderson and Klaassen (2012) & $\mathrm{Da} / \mathrm{Int}$ \\
Azzone and Palermo (2011) & $\mathrm{Da} / \mathrm{Int}$ \\
Baines, Charlesworth, and Cunningham (2014) & $\mathrm{Da} / \mathrm{Int} / \mathrm{Obs}$ \\
Baines, Charlesworth, Turner, and O'Neill (2014) & $\mathrm{Da} / \mathrm{Int} / \mathrm{Obs}$ \\
Cloutier, Denis, Langley, and Lamothe (2016) & $\mathrm{Int} / \mathrm{Obs}$ \\
Gleeson and Knights (2008) & $\mathrm{Da} / \mathrm{Int}$ \\
Goh, Elliott, and Richards (2015) & $\mathrm{Da} / \mathrm{Int}$ \\
Grimaldi and Serpieri (2013) & $\mathrm{Da} / \mathrm{Int}$ \\
Hall et al. (2015) & $\mathrm{Da} / \mathrm{Int}$ \\
Hall and McGinity (2015) & $\mathrm{Int} / \mathrm{Obs}$ \\
Kann-Rasmussen and Balling (2015) & $\mathrm{Int}$ \\
Kartalis, Tsamenyi, and Jayasinghe (2016) & $\mathrm{Da} / \mathrm{Int} / \mathrm{Obs}$ \\
Kinder (2012) & $\mathrm{Da} / \mathrm{Int} / \mathrm{Obs}$ \\
Liff (2014) & $\mathrm{Int}$ \\
Liguori (2012) & $\mathrm{Da} / \mathrm{Int} / \mathrm{Da}$ \\
Malmmose (2015a) & $\mathrm{Da}$ \\
Malmmose (2015b) & $\mathrm{Da}$ \\
Martin, Currie, and Finn (2009) & $\mathrm{Da} / \mathrm{Int} / \mathrm{Obs}$ \\
Mattison and Ramberg (2015) & $\mathrm{Da} / \mathrm{Int}$ \\
Mattison and Thomasson (2007) & $\mathrm{Int}$ \\
Maxcy (2009) & $\mathrm{Da} / \mathrm{Int} / \mathrm{Obs}$ \\
Modell and Wiesel (2008) & $\mathrm{Da} / \mathrm{Int} / \mathrm{Obs}$ \\
Petsoulas et al. (2014) & $\mathrm{Da} / \mathrm{Int} / \mathrm{Obs}$ \\
Sacranie (2012) & $\mathrm{Da} / \mathrm{Int} / \mathrm{Obs}$ \\
Schultz Larsen (2015) & $\mathrm{Da} / \mathrm{Int} / \mathrm{Obs}$ \\
Smith, Richards, Geddes, and Mathers (2011) & $\mathrm{Da} / \mathrm{Int}$ \\
Svensson, Trommel, and Lantink (2008) & $\mathrm{Da} / \mathrm{Int}$ \\
Tummers, Bekkers, and Steijn (2009) & $\mathrm{Da} / \mathrm{Int}$ \\
Tummers, Bekkers, and Steijn (2012) & $\mathrm{Int}$ \\
Wihantoro, Lowe, Cooper, and Manochim (2015) & $\mathrm{Da} / \mathrm{Int} / \mathrm{Obs}$ \\
\hline
\end{tabular}

Note: $\mathrm{Da}=$ Document analysis

Int $=$ Interviews

Obs $=$ Observations

Table 3. Mixed method empirical studies referencing Hood and Peters (2004)

\begin{tabular}{lc}
\hline Article reference & $\begin{array}{c}\text { Method of data } \\
\text { collection }\end{array}$ \\
\hline Ahlbäck and Bringselius (2015) & $\mathrm{Da} / \mathrm{Int} / \mathrm{Ques}$ \\
Caraker, Jorgensen, Madsen, and Baadsgaard (2016) & $\mathrm{Da} / \mathrm{Int} / \mathrm{Ques}$ \\
Schmid, Dolev, and Szabo-Lael (2010) & $\mathrm{Da} / \mathrm{Ques}$ \\
Shin, Kim, Lim, Shim, and Choi (2015) & $\mathrm{Int} / \mathrm{Ques}$ \\
& $\mathrm{Da} / \mathrm{Int} / \mathrm{Ques}$ \\
\hline
\end{tabular}

Note: Da $=$ Document analysis

Int $=$ Interviews

Ques $=$ Questionnaire 
We first studied the way in which the content of the change was included. It appeared that some studies do not define this content at all, because they do not actually go into a concrete change process. Examples are Baines, Charlesworth and Cunningham (2014), Grimaldi and Serpieri (2013) and Kann-Rasmussen and Balling (2015). Other articles study organizational change without explicating the actual change content (Hall \& McGinity, 2015; Kinder, 2012), or they define a change initiative in rather abstract, mostly macro-level or political terms (Cloutier et al., 2016; Hall et al., 2015; Liguori, 2012; Mattison \& Ramberg, 2015; Sacranie, 2012). Five studies appeared to define the change content in detail: Azzone and Palermo (2011), Gleeson and Knights (2008), Liff (2014), Schmid et al. (2010) and Schultz Larsen (2015).

We then analysed how context is described in these 36 studies. It appeared that context usually figures only in general terms; see, for example, Almqvist et al. (2011) and Cloutier et al. (2016). There were four exceptions: Ahlbäck and Bringselius (2015); Anderson and Klaassen (2012); Azzone and Palermo (2011); Schultz Larsen (2015). These four studies do investigate specific contexts in detail, and it must be added that Schultz Larsen's (2015) study is the only one that defines the change content in detail as well (see above). However, none of the authors, Schultz Larsen included, provides a substantive justification for the reasons why the contextual elements actually described were selected. This means that we could not adequately figure out the substantive cohesion from their descriptions, and as a result, their descriptions appeared rather fragmented. For example, Anderson and Klaassen (2012) investigate how context affects output management effectiveness. The authors work out context in terms of the degree of agreement on objectives, insight into the transformation process, specificity of output definition and political sensitivity. They justify these factors by pointing to other studies which claim that these factors affect output management effectiveness. However, the authors do not even begin to make plausible that these four factors are the only contextual elements that affect output management effectiveness; and besides, these factors are abstractions in themselves and were operationalized only vaguely in this study.

In the four studies that describe context in detail, we studied the methods of data collection, and we concluded that these fragmented descriptions are the result of a rather limited operationalization, and therefore limited investigation of the context. Yet, some studies use a method that makes it possible - at least in theory - to develop a fuller view of the context. For example, Schultz Larsen's study (2015) is based on one year of ethnographic fieldwork, which would have enabled the author to give a detailed description of the context. But his factual description gives just a narrative of the limited time lapse of the change process itself. Since no broader contextual data are presented, the reasons given for the outcome of the change process are, to say the least, questionable. In other words, the author cannot or does not explicate whether the examples and quotes given really and validly represent the context investigated.

\subsection{Summarizing Results and Conclusion}

Our conclusion that only 17 percent of the studies in our sample are empirical, is perhaps the 
most telling result of our research. As others have concluded earlier (Pawson, 2013; Pollitt \& Dan, 2011), we feel that this low percentage is a manifestation of the rather abstract and rhetorical level of NPM discourse on change - which may well explain the lack of a clear conceptualization of context as well. An analysis of the empirical studies showed that only one quantitative study (Willem \& Buelens, 2007) deals with some contextual factors, within the limits of quantitative methods as such, more than other quantitative studies, but it fails to conceptualize context, and this means it is another instance of a fragmented approach.

The results of the qualitative and mixed method studies we screened show that only one study (Schultz Larsen, 2015) produces a detailed description of the content of both change and context, while all the other studies, though paying a little more attention to context than the quantitative studies, conceptualize context equally poorly, and their descriptions are similarly abstract or fragmented. We would submit that the problem of the abstract and fragmented approach to context could be resolved if these studies used a description of the change content as a framework in which the context should be described. We will return to this argument later in this paper.

If the lack of a detailed survey of the content of both change and context has such important consequences as Pollitt (2003) argues - too many failing NPM initiatives - the question is why scholars have not been able to make theoretical and methodological contributions for improving their contextual analyses. The next section addresses this problem, and may offer some material for our theoretical and methodological contribution to contextualizing change initiatives, to be presented in the section after that.

\subsection{Abstract or Fragmented, Why Is That?}

It is our estimate that the rather abstract or fragmented approach to context must be attributed to what Hood and Peters call the "broad-brush normative concerns" (2004, p. 267), and to the corresponding practices that have preoccupied NPM and NPM theorizing from its earliest stages. We must add, though, that through the years, some sensibility for paradox has developed. In an edited volume on context in public policy and management, Pollitt (2013, p. 215) rhetorically asks how many reliable generalizations the so-called anti-contextualists have produced over the last decades before they finally started to explore the explanatory link of what attention to context - in whatever form - can mean in the chain from public administration policy interventions to performance and supposed outcomes. In the same volume, Hood traces the history of context in organization studies (e.g. contingency theory), which can help overcome the damage of a one-size-fits all approach of "public management by numbers" (2013, p. 116). His plea for a cultural approach based upon anthropologist Mary Douglas's grid-group scheme (Douglas, 1996) is an indication that what lies behind NPM's failure to live up to its claims is exactly the negligence of cultural context at group level. Flynn (2002) has already made a similar point, emphasizing the importance of both national cultures and the more local political and cultural climate, or, as Verhoest $(2011$, p. 1) formulates, "implementation habitats".

It is precisely this local observable reality that is conspicuously lacking in the NPM approach to organizational change, because - we think - that is exactly the domain where interpretation 
of reality by organizational actors becomes relevant, the interpretation the unpredictability of which sits uneasily with the allegedly objective NPM principles. An informative example of the lacking of this local interpretation of reality by organizational actors is the model of public management reform, developed by Pollitt and Bouckaert (2017, p. 33). In this model, concrete observable workplace practices remain out of sight, which, in fact, is in sync with the absence of references to the workplace reality in their definition of public management reform, cited in our introduction. Our argument is that the NPM discourse need a fundamental rethinking of both its concepts and its approach to implementation, because it is this reality - accounting for place, time, actors, substance, and so on - that is largely missing, not only in the empirical studies discussed above, but in the debate on a more conceptual level as well. What we need is an approach that can justly claim some deeper understanding as well as more accurate predictions of future developments, and at the same time claim a more modest scope and incorporate more complexity and ambiguity (Virtanen, 2013). Anthropological approaches are particularly relevant at this level of 'situated activity' (Layder, 2006), where (individual) actors draw from cultural repertoires of meaning to interpret what happens in their environment. This interpretation is - in Dilley's words - "the act of creating connections", and context then just means "sets of connections construed as relevant to someone" (1999, p. 2). Dilley then uses Scharfstein's definition of context as "that which environs the object of interest and helps by its relevance to explain it" (p. 3). This is what we might call 'cultural connections of relevance', which is central to the argument of cognitive anthropology, the field from which the $\mathrm{CC}$ approach has been drawn.

\section{Development of the CC-Framework}

We already concluded that the notion of 'organizational context' is hardly conceptualized by many of the authors named or cited in the previous section. It is obvious that we must avoid this pitfall in an analysis of the context of NPM reform initiatives. Besides, given our ambition to explain the relation between change content and context in general, we have to theorize on this at a fundamental level. Our attempt at conceptualizing on the level of 'organizational context' runs as follows: the organizational context is the pattern of connections and interpretations among and between employees, representing their behaviour when they act in the local workplace. We would conceptualize public management reform as a change of this pattern of connections and interpretations, representing a change in their behaviour. This definition respects the simple truth that any change in output or outcome of an organization, public or private, must be the result of altered workplace practices. This reconceptualization of the notion of 'context' and 'reform' was inspired by notions of culture prevalent in cognitive anthropology.

\subsection{Introducing Cognitive Anthropology}

In his book Explaining Culture: a naturalistic approach, (Sperber, 1996) the cognitive anthropologist Dan Sperber advocates an anthropology that is enriched by certain elements from cognitive psychology that help explain the causes and effects of change on a cognitive level. A key concept in his approach is 'cultural environment' (p. 115), which consists of 'cultural things' (p. 24) and mental representations. Cultural things exist in reality, in two 
different sorts of elements: first, the modifications of the environment; and second, human behaviour that brings about these modifications. They are both causes and effects of mental representations.

Sperber elaborates this cognitive approach to culture on two levels, an individual level and a group level. At the individual level, someone's interaction with cultural things triggers the construction of mental representations, and that is how the cultural things obtain or retain their meaning. In Sperber's (1996) naturalistic approach cultural things as well as mental representations are considered to have material aspects. Cultural things have, of course, a material aspect because they can be perceived by the senses. According to Sperber, mental representations have material aspects as well, they are “(...) brain states described in functional terms, and it is the material interaction between brains, organisms and environment which explains the distribution of these representations" (1996, p. 26).

In the pages that follow, we will use the more common notion of mental models instead of mental representations. So, someone's mental models consist of interpretations of the environment in which he or she acts. Mental models represent someone's behaviour, which then becomes effective within his or her environment and create new cultural things, or changes these, if necessary. Saying that someone's mental models determine his or her behaviour within the environment in which he or she acts, means that we extend Sperber's (1996) notion of cultural things containing all environmental elements, whether they are brought about by human behaviour or not, and that we consider other human beings part of this environment.

In the case of group level, we assume that in each group of people acting together in a shared environment, there is a common denominator of mental models. The more equal the mental models existing between different individuals are, the more likely it is that these models are part of the cultural environment they share.

From the (short) introduction of Sperbers' (1996) naturalistic approach we can conclude, that his notion of 'cultural environment' bears a strong resemblance to the notion of 'context' as defined in the previous paragraph. Using his approach, we can develop cause-effect mechanisms that help to predict the likelihood of change of the context and, consequently, the likelihood of behavioural change.

\subsection{How Can Behavioural Change Be Explained?}

Now that we have a theoretical basis of our conceptualization of 'context', we can do the same for the notion of 'change'. First, we look at how a change in workplace practices takes place on an individual level. We assume that a change in behaviour of a certain person (an employee in a local workplace, for instance) is always represented by a change in his or her mental models. Basically, someone's behaviour changes when the content of the change is integrated into his or her set of existing mental models, which causes a transformation of existing models or the creation of new models. The more meaningful the change content appears to be, the more it will succeed in becoming the dominant source of new or transformed mental models. In Sperber's (1996) terms, the content of a change appears 
'cognitively relevant'. He says that the balance between effect and effort in the cognitive processing of new information determines the level of relevance. Cognitive processes are set to maximization of relevance, with the least possible effort.

If we accept this theory for predicting behavioural change of an employee acting within a local workplace, the following is what happens: the cognitive process of an employee transforms the content of an initiative for change in such a way that it either produces a repeat of the desired effect within his or her local workplace, or it makes the interaction with the objects of this workplace more effective, with the least possible effort. In the first case, the content of the change will be transformed and adapted to the mental models, which are strengthened and remain unchanged. In the second case, the content of the change can satisfy certain needs. The current mental models will be transformed, using this content, in order to enhance the interaction with the object of the workplace. The content of a change that can only be transformed after much effort or cannot be changed at all, is unlikely to be included in the new set of mental models of the employee.

We now look at behavioural change on a group level, for instance employees acting together within a local workplace. Sperber (1996) maintains that behavioural change is represented by a change of mental models of a group of people. According to him, a change in mental models should be analysed as a diffusion process, because the question why some mental models happen to be contagious while others are not, is basically an epidemiological process. So, the process of behavioural change of a group of people is represented by an epidemiological process of their mental models. In biological epidemiology, the dissemination of information generally occurs by copying (replication). According to Sperber (1996), dissemination of mental models within a group of people does not happen by replication, but is based on the transformation process on the individual level that is determined by cognitive relevance. In other words, cognitive relevance determines the diffusion of a change in a shared context.

We are aware that in this construction of our CC-framework, inspired by Sperbers' (1996) ideas and notions, we somewhat simplify the pure epidemiological approach, in that we treat the change process of a shared context as if it were one's individual context. We also ignore the individual cognitive-psychological variability, because for convenience' sake we assume that the cumulative effect of this variability on the shared context at the population level is neutral.

We use the notion of cognitive relevance to its full extent, in order to assess the impact of the content of a change on the shared context. The relevant question here is as follows: Is the impact of the content of a projected change a reinforcement of current behaviour within the local workplace, or does it lead to an interaction within the workplace that is more effective at the lowest possible effort? The answer to this question predicts whether, and if so, to what extent the shared context and consequently the shared behaviour within the workplace will change.

Given the cognitive anthropological theory sketched above, we can now develop a generic NPM reform framework of cause-effect relations and a research method to investigate the 
diffusion of a NPM reform initiative in particular cases. We referred to this generic approach, the framework and the research method as Cognitive-Cultural, bearing in mind that a shared context can be seen as a culture.

\subsection{CC-Framework}

In the CC-framework, as depicted in Figure 1, the current behaviour of employees acting together within a local workplace is represented by their (current) shared context.

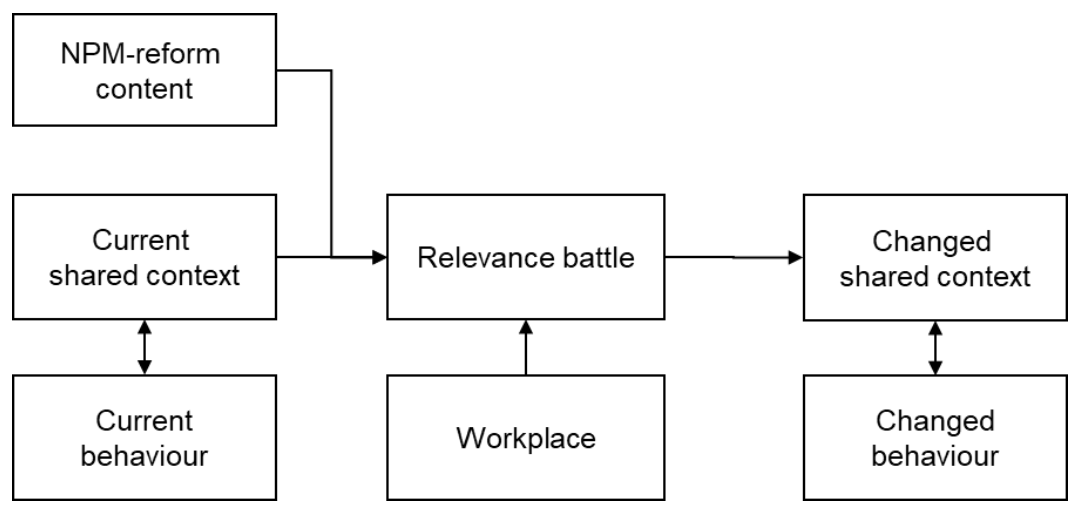

Figure 1. CC-framework

Their behaviour is, to a certain extent, cognitively relevant within the workplace, as a result of which people can do their tasks. If someone within the organization (e.g. the general manager) is planning to initiate a NPM inspired change, the content of this change will be cognitively relevant, to the extent that it may reinforce the existing shared context or lead to more effective interaction within the workplace. In the latter case, it will become part of the changed context, and then behaviour will change accordingly.

With workplace we mean the physical environment within which the group of people act together. It is important for determining whether people experience obstacles when acting in compliance with the current context. If this is the case, then mismatches are likely to arise between people's behaviour and this workplace, resulting in a decline of the cognitive relevance of the context, and in an improvement in the conditions for change. In situations like that, a new NPM reform stands a good chance of surviving the 'relevance battle' with the current shared context, 'infecting' it with new representations, new action strategies, and new shared behaviour. Analogous to the 'survival of the fittest' in biological epidemiology, the content of an NPM reform will meet with easier reception in the workplace and will, therefore, become the new source of shared context necessary for acting in the workplace.

Although this framework assumes that the prevailing shared context and the content of the NPM inspired change emerge from different cultural premises, it is to be expected that similarities and continuity can also be found between them, especially in situations where changes were designed and formulated by people who act in the same workplace. Nevertheless, the purport of NPM reform is always bringing about changes in certain behaviours represented by the context, or introducing new ones.

By means of this framework, we intend to explain, and to some extent predict, the possible 
effects of change efforts. This does not mean that the 'relevance battle' is considered as the only process determining the course of change. All change processes consist of a complex mix of policies, practices, cognitions, emotions, and so on (Spillane, Brian, \& Reimer, 2002). However, our framework focuses on the intrinsic aspects of the change and can, therefore, be regarded as an addition to the existing theories of change management.

\subsection{Research Method}

Now that this CC-framework is available, the question is how this framework can be of importance in NPM reforms. For that purpose, we need to find a method for analysing the relevance battle. The $\mathrm{CC}$ research method we developed, is depicted in Figure 2. It consists of a number of analyses that, taken together, can be characterized as a mixed method (Greene \& Hall, 2010; Robson, 2002; Tashakkori \& Teddlie, 2010). First, the planned NPM change is mapped by means of a descriptive model of concepts and their relationships. Since we focus on NPM reforms that are initiated by the management of a public organization, we ensure that management actively guides the definition of the content of the change by means of the desired selection of interviewees: those who are to be managers or members of supporting staff, and by approval afterwards.

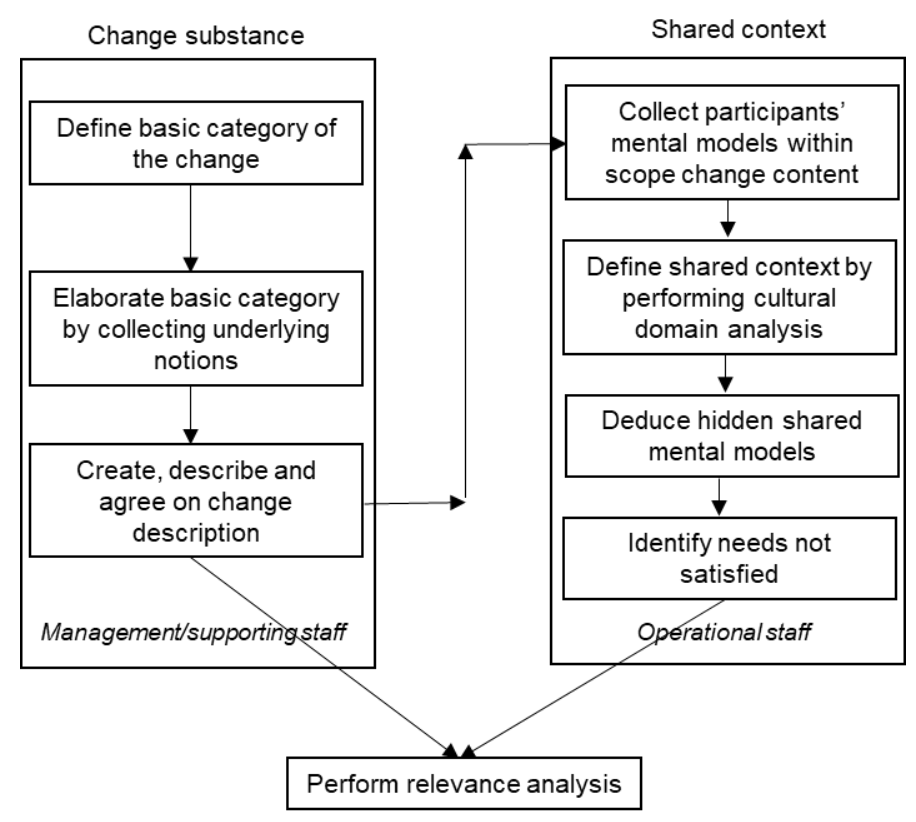

Figure 2. The CC research method.

After the definition of the content of the change, let us have a look at the shared context. This is defined in four steps. In the first step, "collect participants' mental models within scope of the change content", the operational staff members are interviewed. The categories in which the change content is classified, determine the domain of this investigation. In the second step: 'define the shared context by doing a cultural domain analysis', a questionnaire is constructed and distributed, which is based on the collected mental models. The results of the questionnaire are analysed by means of the informal analysis model of the Cultural Consensus Theory (Romney, Weller, \& Batchelder, 1986). According to Weller and Romney (Weller \& Romney, 1988, p. 75), “A central assumption of the consensus model is that the 
correspondence between any two informants is a function of the extent to which each has knowledge of the culturally correct answers". In accordance with Weller and Baer (2002), the participants are considered to have the same context if the first Eigenvalue in a principal components analysis is substantially greater than the second. This analysis leads to a set of 'culturally true' notions or statements, which constitute the shared context.

For the third and fourth steps: 'deduce hidden shared mental models' and 'identify needs not satisfied', a small number of operational staff members are observed and interviewed. The participants are selected, on the basis of their cultural competence coefficient (Collins \& Dressler, 2008; Romney et al., 1986). Participants with the highest cultural competence coefficient are selected, because they are considered to be the best representatives of the shared context. We would argue that the third step is optional. Argyris and Schön (1974) have shown that there may be a gap between espoused theories about what people think they do on the one hand, and the theories in use, which actually determine behaviour, on the other. Eraut (1994) applies this difference to certain working situations where decisions need to be made intuitively, for instance when immediate action - 'hot action' (p. 53) - is required. Because people are not aware of the mental models used in these situations, they cannot be collected by interviewing alone. Additional observation is needed. The results of these observations may have a substantial impact on the relevance analysis.

In the fourth step, the same participants are interviewed in order to identify the alignment of the ideological and cultural correct statement (including hidden mental models deduced before) with the workplace, which leads to a number of needs not satisfied within the domain of investigation.

The last part of the CC-method deals with relevance analysis. The content of the change and the shared context are compared in two different aspects: To what extent are the change notions or statements easily transformable into current cultural correct notions or statements, leaving the current notions unchanged? And, to what extent can the change notions or statements easily enhance the efficacy of the interaction with the workplace, resulting in current cultural correct notions or statements that are likely to be adjusted? From this analysis, conclusions can be drawn about the probability of the success of the realization of the change as a whole, and of its different elements.

\section{Application of the CC-Method}

We have now shown how the CC-framework provides a theoretical and methodological answer to the central question of this paper, and may contribute to a relevant analysis of context and change, as Pollitt (2003) suggested. We have applied the CC research method in two case studies, which can be characterised as representative NPM-reform initiatives. These studies were carried out in two schools in the Netherlands. In both studies, we observed the route as depicted in Figure 2. We present some examples of the results that can be obtained using the CC research method.

In the first case, the management team of a school for secondary education was under pressure to enhance school results. The core of their change initiative consisted in improving 
the individual professionalism of the teachers. They labelled the change 'professional learning culture'. The relevance analysis resulted in serious doubts about the chances of viability of the change in the relevance battle. In this case, however, we drew this conclusion only in the second instance. At first, core elements of the change content seemed to be in sync with the teachers' shared context. But after several hours of observing the teachers' behaviour in and outside the classroom, we deduced that under the skin there were mental models that differed from the teachers' espoused context (see Figure 2, right part, third step). We observed that elements such as 'being strict' and 'being focused on learning results' were representations of rather different behaviours. The teachers did not appear to be aware of these differences. In other words, the teachers showed different types of behaviour, but used the same notions to describe it. This may well mean that in practice, the corresponding elements of the change would not have the reinforcing influence that we initially expected.

Other elements of the change did not seem to be connected to the teachers' shared context. For instance, in the content of the change, the teacher is a decisive factor in enhancing learning results; but the teachers seemed satisfied with their own efforts to gain educational results, while externalising the causes of poor educational results to the pupils' lower social background. The change content also emphasised some specific elements in teacher development, whereas the teachers themselves did not feel that their personal development should be a subject for discussion in the school or that it was relevant to enhancing learning results. The change stressed the importance of learning from each other, peer learning and attending each other's lessons, but these elements do not figure in the teachers' shared context.

In the second case, which Wierenga, Kamsteeg, Simons and Veenswijk (2013) reported on in detail, the question was to what extent result-oriented teacher teams were likely to be formed in a school for vocational education and training. The results of the relevance analysis showed that the change content conflicted with substantial aspects of the existing shared context of the school in question, and failed to meet not yet satisfied needs within this context. Consequently, the cognitive relevance of this change proved to be limited. This conclusion could be drawn because both the change content and the teachers' shared context were elaborated in great detail, and could therefore be compared on that level. It emerged that, while the change content addressed the need to enhance the results on the school level and considered teacher team membership as a prerequisite, the teachers' context pointed rather to individual commitment to subject matter, colleagues, and student development. It seems justified to conclude that it was highly improbable that the introduction of result-oriented teams was going to survive in the 'relevance battle' with the teachers' shared context in this institution. As this study had been conducted in the pre-implementation stage of this NPM-inspired intervention, we concluded that this negative prediction should carry some weight in the way in which management would try to implement the change.

The relevance analysis further suggested that certain elements of the change content did in fact have some relevance. Elements such as giving more freedom to teams in developing and planning their own scenarios, paying attention to student differences, and the need to implement one or more school minors, all did align with teachers' shared context, while the 
element 'being in control' was to a certain extent cognitively relevant because in the current context the teachers were facing more and more trouble with their time allocation. It seems appropriate, therefore, to emphasise the importance of paying attention to the elaboration and implementation of change elements that have evidently cognitive relevance, perhaps with special attention to those that are relevant for several reasons. Once elements of a change project that were cognitively relevant have been tackled, it may appear that this may eventually lead to successfully implementing other elements, even if they initially lacked relevance.

\section{Implications for the NPM Discourse}

\subsection{Implications for NPM Reform Practice}

As indicated before, the development of the CC approach started with Pollitt's (2003; 2013) advice to carry out a careful analysis of the context in which public management reform is to take place. We have shown that a detailed description of the context, plotted against a proper definition of the change content, is conspicuously missing in the current NPM reform debate. We argued that this is caused by the unpredictability of interpretations of the organizational actors, an unpredictability which sits uneasily with the presumably objective NPM principles. On top of that, there is also the assumption that "contextual factors may have great explanatory capacity but they also prevent generalization" (Pierre, 2013, p. 127). With the $\mathrm{CC}$-approach, we have designed an alternative basis to reconceptualise NPM reform by placing the context in the centre of the analysis, not as just one of a cluster of factors, but as common denominator of patterns of interpretations that drive people's behaviour. In general, we must agree that generalization is problematical if context is considered as an independent factor. By modelling the relations between cognitions, behaviour and environment, as we do in the CC-framework, we avoid this problem.

Pollitt and Dan (2013, p. 22) stated that "it would be mistaken to dismiss NPM as a failure. [...] Would-be reformers need to look rather hard at several dimensions of the local context before they decide that NPM is the answer to their problems (and certainly before they decide how to implement it)". We would like to add, that a relevance analysis - as part of our CC research method - should be performed in every case defined by these would-be reformers, not only to decide if NPM is the answer, but also to decide how to implement it. It offers valuable information that enables us not only to assess the overall cognitive relevance of NPM-reforms, but also to make assessments at the level of their underlying elements. Some change initiatives that do not have any cognitive relevance can be buried safely, before the misery of failed implementation will backfire on organizational performance. Other NPM change initiatives can - perhaps partly - be implemented successfully because it is clear what would have to change at the behavioural level, while its relevance has been estimated as sufficient.

Pollitt and Bouckaert (2017, p. 76) argue that "fully worked out scenarios [initial situation, trajectory, future situation] are the exception rather than the rule in public management reform". As a result, assessing reform results appears problematic. We would plea that NPM reformers use the $\mathrm{CC}$ research model to get to grips with the complexity of both the initial 
situation (context) and the future situation (content). This implies that the often rather abstract elements of a NPM reform should be considered in relation to the more concrete level of the context. Detailed elaboration in itself will not always do the trick here, but it should be made explicit that new elements do not simply address a series of collateral 'non-issues', apart from the one problem that is truly cognitively relevant for the employees.

We would like to give some examples how our CC-approach can be beneficial, and then look at the studies we mentioned in the study-analysis section. First, our definition of context can be useful in studies that define context in too abstract a manner, or do not define context at all. We concluded above, for instance, that Anderson and Klaassen (2012) do actually go into the context, but remain rather abstract. In spite of that, they conclude that the context is less important for the efficacy of Dutch municipalities than the type of output management. It is questionable whether this conclusion would be drawn if the context had been defined and investigated as we suggest, especially because - as they admit themselves - their findings differ from the existing literature.

Using our CC research method could have similar effects if applied to the study undertaken by Cloutier et al. (2016), who investigate the extent to which the four elements of the institutional work done by health care managers influence NPM reform implementations, and conclude that one of these elements, 'relational work', is an underpinning and determining factor to effectuate change. Relational work is described as building linkage, trust and collaboration between people involved in the actual change. Their data collection was done by interviewing managers, attending management meetings and document analysis. Our CC research model provides an alternative way of valuing the type of data that has actually been collected. These data consist of a number of managers' mental models, which may or may not reflect their behaviour and which may or may not be shared within the group of managers. This raises the question whether, and to what extent these managers in fact build linkages, trust and collaboration. It also shows that this study does not investigate how people in the workplace perceive what their managers are doing. And since this study does not investigate the content of the change in detail, it is unclear against which reference the conclusion is drawn that relational work determines change. Close investigation of both the change and the shared mental models, reflecting the actual behaviour of both the managers and the people involved, would have provided the real factors of the causes for successful change.

A last example of the use of our CC approach is given in the case of Kinder (2012). Although the author does not define the content of the change at hand, nor the mental models of the people involved, his definition of context comes close to our concept of a shared meaning system. Moreover, in his 'listening and learning innovating framework' (p. 407), resonates the view that change is a matter of learning in context. In our CC-framework, a change of behaviour is the result of 'infecting' mental representations with new action strategies, which can, in fact, be considered as another description of learning (Driscoll, 2005). We would suggest that the author could improve his theoretical framework and analysis by being more specific about what should be learned in concrete situations, for which our CC research method may be helpful. 
From our study of recent NPM reform literature and our critical comments on the mostly superficial and abstract elaborations of context in the quantitative studies, we may conclude that quantitative research methods are useless for NPM-scholars who are prepared to honour the importance of context. Yet this is not what we intend to argue. For an impressive quantitative study that honours context, we want to give an example which is not included in the sample that we have used for this paper. Sun and Van Ryzin (2014) describe a large-scale quantitative research project which provides evidence for a positive correlation between performance management practices and school results in the city of New York. When they developed a questionnaire for performance management practices, they used the New York City Department of Education's quality review, which is conducted by a team of experienced and trained reviewers who perform observations of a wide range of activities in more than a thousand schools. Considering the fact that for most researchers such a large dataset would probably not be available, our CC research method provides an alternative base for developing the underlying questionnaire that requires substantially less effort.

\subsection{NPM Reform as an Emergent Change Process}

The notion of cognitive relevance as an important factor determining success or failure of change processes implies that any NPM reform has certain characteristics of an emergent process (Pettigrew, Woodman, \& Cameron, 2001; Van der Voet, Groeneveld, \& Kuipers, 2014). In fact, the idea behind the CC approach is to provide empirical data that may help to predict the emergence of particular NPM reform initiatives. This does not mean that the change management and leadership in the NPM discourse could not benefit from this. The $\mathrm{CC}$ research method can indeed be helpful in sequencing the change steps; for instance, starting with the more relevant change elements. It may also provide information for making adaptations to the physical environment before initiating the next steps in the change process.

On a theoretical level, the CC-framework aligns with views that are based on assumptions of the complexity instead of linearity of change management processes (Higgs \& Rowland, 2007) and the integrative approach to change leadership (Gill, 2002). It also tallies with the ideas behind the Emerging Change Model (Lawrence, 2015), especially the conception of NPM change processes as action-mediated by purpose, perspective and identity. The relevance battle of the CC-framework can be understood as the underlying cognitive process of the reflective dialogue between the people involved, which determines to what extent a NPM reform will emerge. The CC-research method may, therefore, offer a procedure to analyse the patterns of this dialogue. It may also establish the connection between the perspectives of those involved and their behaviour, which seems to be missing in the authors' model.

\subsection{Next Steps in NPM Research}

James C. Scott stated that: "The lack of context is not an oversight; it is the necessary first premise of any large-scale planning exercise" (1998, p. 346). Our analysis of the current NPM literature reveals that in today's NPM literature, context still finds itself in this subordinate position. Although we argue that context is a decisive factor for success in any change initiative, this does not mean that we see no future for centrally-initiated change as a 
means of improving the output and results of public services. Our argument is that we have to thoroughly rethink the way in which NPM reform should be conceptualized and implemented, in order to fulfil its ambitions. We believe that the CC approach, which has indeed been developed primarily for micro-level projects - where local management defines the content of the NPM change and has practical possibilities to investigate their particular context -, provides the building blocks for a total makeover of these large scale implementation efforts. The first step could be an apparently small, but significant change in Pollitt and Bouckaert's (2017) definition of NPM reform: Deliberate attempts to change the workplace practices in public sector organizations, with the objective of getting them (in some sense) to run better. We invite NPM researchers to leave behind the world of abstractions and to embark on this fundamental return to the observable reality, in order to really improve public services.

\section{References}

Adams, C. A., Muir, S., \& Hoque, Z. (2014). Measurement of sustainability performance in the public sector. Sustainability Accounting Management and Policy Journal, 5(1), 46-67. https://doi.org/10.1108/SAMPJ-04-2012-0018

Ahlbäck, S., \& Bringselius, L. (2015). Professionalism and organizational performance in the wake of new managerialism. European Political Science Review, 7(4), 499-523. https://doi.org/10.1017/S1755773914000307

Almqvist, R., Catasús, B., \& Skoog, M. (2011). Towards the next generation of public management; A study of management control and communication in the Swedish Armed Forces. International Journal of Public Sector Management, 24(2), 122-145. https://doi.org/10.1108/09513551111109035

Anderson, R., \& Klaassen, H. (2012). The fallacy of the context; An empirical study of the influence of the context on the use of performance management in the public sector. International Journal of Productivity and Performance Management, 61(5), 483-501. https://doi.org/10.1108/17410401211232939

Argyris, C., \& Schön, D. A. (1974). Theory in practice: Increasing professional effectiveness. San Francisco: Jossey-Bass.

Aristigueta, M., \& Van Dooren, W. (2007). Toward a performing public sector - the roles of context, utilization and networks. Introduction. Symposium. Public Performance and Management Review, 30(4), 463-468. https://doi.org/10.2753/PMR1530-9576300400

Azzone, G., \& Palermo, T. (2011). Adopting performance appraisal and reward systems; A qualitative analysis of public sector organisational change. Journal of Organizational Change Management, 24(1), 90-111. https://doi.org/10.1108/09534811111102300

Baines, D., Charlesworth, S., \& Cunningham, I. (2014). Fragmented outcomes: International comparisons of gender, managerialism and union strategies in the nonprofit sector. Journal of Industrial Relations, 56(1), 24-42. https://doi.org/10.1177/0022185613498664 
Baines, D., Charlesworth, S., Turner, D., \& O'Neill, L. (2014). Lean social care and worker identity: The role of outcomes supervision and mission. Critical Social Policy, 34(4), 433-453. https://doi.org/10.1177/0261018314538799

Caraker, E., Jorgensen, H., Madsen, M. O., \& Baadsgaard, K. (2016). Representation without co-determination? Participation and co-determination for semi-professional shop stewards in the collective participation system in Denmark. Economic and Industrial Democracy, 37(2), 269-295. https://doi.org/10.1177/0143831X14538527

Chirici, G. (2012). Assessing the scientific productivity of Italian forest reserachers using the Web of Schience, SCOPUS, and SCIMAGO databases. iForest Biogeosciences and Forestry, 5, 101-107. https://doi.org/10.3832/ifor0613-005

Cloutier, C., Denis, J. L., Langley, A., \& Lamothe, L. (2016). Agency at the Managerial Interface: Public Sector Reform as Institutional Work. Journal of Public Administration, Research and Theory, 26(2), 259. https://doi.org/10.1093/jopart/muv009

Collins, C. C., \& Dressler, W. W. (2008). A mixed methods investigation of human service providers' models of domestic violence. Journal of Mixed Methods Research, 2(4), 362-387. https://doi.org/10.1177/1558689808322766

Dilley, R. M. (Ed.) (1999). The Problem of Context. New York, Oxford: Berghahn.

Douglas, M. (1996). Natural Symbols; Exploration in Cosmology, with new introduction. London: Routledge.

Driscoll, M. P. (2005). Psychology of Learning for Instruction (3rd ed.). Boston: Pearson Education, Inc.

Eraut, M. (1994). Developing Professional Knowledge and Competence. Oxon: RoutledgeFalmer.

Fekete, C., Siegrist, J., \& Tough, H. (2017). Social relationships, mental health and wellbeing in physical disability: a systematic review. BMC Public Health, 17(1), 1-18.

Flynn, N. (2002). Explaining the New Public Management: the importance of context. In K. McLaughlin, S. P. Osborne, \& E. Ferlie (Eds.), New Public Management. Current trends and future prospects (pp. 57-76). London: Routledge.

Gill, R. (2002). Change management--or change leadership? Journal of Change Management, 3(4), 307-318. https://doi.org/10.1080/714023845

Gleeson, D., \& Knights, D. (2008). Reluctant Leaders: An Analysis of Middle Managers' Perceptions of Leadership in Further Education in England. Leadership, 4(1), 49-72. https://doi.org/10.1177/1742715007085769

Goh, S. C., Elliott, C., \& Richards, G. (2015). Performance management in Canadian public organizations: findings of a multi-case study. International Journal of Productivity and Performance Management, 64(2), 157-174. https://doi.org/10.1108/IJPPM-10-2013-0170 


\section{Macrothink}

Journal of Public Administration and Governance ISSN 2161-7104 2018, Vol. 8, No. 1

Greene, J. C., \& Hall, J. N. (2010). Dialectices and pragmatism; Being of consequence. In A. Tashakkori \& C. Teddlie (Eds.), Mixed Methods in Social \& Behavioral Research (pp. 119-143). Thousand Oaks: Sage Publication, Inc. https://doi.org/10.4135/9781506335193.n5

Grimaldi, E., \& Serpieri, R. (2013). Jigsawing education evaluation. Pieces from the Italian New Public Management puzzle. Journal of educational Administration and History, 45(4), 306-335. https://doi.org/10.1080/00220620.2013.822350

Hall, D., Grimaldi, E., Gunter, H. M., Moller, J., Serpieri, R., \& Skedsmo, G. (2015). Educational reform and modernisation in Europe: The role of national contexts in mediating the new public management. European Educational Research Journal, 14(6), 487-507. https://doi.org/10.1177/1474904115615357

Hall, D., \& McGinity, R. (2015). Conceptualizing Teacher Professional Identity in Neoliberal times: Resistance, Compliance and Reform. Education Policy Analysis Archives, 23(88), 1-17. https://doi.org/10.14507/epaa.v23.2092

Higgs, M., \& Rowland, D. (2007). All change great and small: Exploring approaches to change and its leadership. Journal of Change Management, 5(2), 121-151. https://doi.org/10.1080/14697010500082902

Hood, C. (1991). A public management for all seasons. Public Administration, 69, 3-19. https://doi.org/10.1111/j.1467-9299.1991.tb00779.x

Hood, C. (2013). Can cultural theory give us a handle on the difference context makes to management by numbers? In C. Pollitt (Ed.), Context in Public Policy and Management: the Missing Link? (pp. 115-123). London: Edgar Elgar. https://doi.org/10.4337/9781781955147.00017

Hood, C., \& Peters, G. (2004). The Middle Aging of New Public Management: Into the Age of Paradox? Journal of Public Administration, Research and Theory, 25(1), 267-282. https://doi.org/10.1093/jopart/muh019

Kann, R. N., \& Balling, G. (2015). Every reader his book - every book its reader? Notions on readers' advisory and audiance development in Danish public libraries. Journal of Librarianship and Information Science, 47(3), 242-253. https://doi.org/10.1177/0961000614532486

Kartalis, N., Tsamenyi, M., \& Jayasinghe, K. (2016). Accounting in new public management (NPM) and shifting organizational boundaries; evidence from the Greek Show Caves. Accounting, Auditing \& Accountability Journal, 29(2), 248-277. https://doi.org/10.1108/AAAJ-05-2014-1707

Kinder, T. (2012). Learning, Innovating and Performance in Post-New Public Management of Locally Delivered Public Services. Public Management Review, 14(3), 403-428. https://doi.org/10.1080/14719037.2011.637408 
Lawrence, P. (2015). Leading Change - Insights Into How Leaders Actually Approach the Challenge of Complexity. Journal of Change Management, 15(3), 231-252. https://doi.org/10.1080/14697017.2015.1021271

Layder, D. (2006). Understanding Social theory. London: Sage Publications. https://doi.org/10.4135/9781446279052

Liff, R. (2014). Unintended Consequences of NPM Drive the "Bureaucracy". International Journal of Public Administration, 37(8), 474-483. https://doi.org/10.1080/01900692.2013.865644

Liguori, M. (2012). The Supremacy of the Sequence: Key Elements and Dimensions in the $\begin{array}{llll}\text { Process of } \quad \text { Change. } & \text { Organization } & \text { Studies, } & 33(4),\end{array}$ https://doi.org/10.1177/0170840612443457

Malmmose, M. (2015a). Management accounting versus medical profession discourse: Hegemony in a public health care debate - A case from Denmark. Critical Perspectives on Accounting, 27, 144-159. https://doi.org/10.1016/j.cpa.2014.05.002

Malmmose, M. (2015b). National hospital development, 1948-2000: The WHO as an international propagator. Accounting History Review, 25(3), 239-259. https://doi.org/10.1080/21552851.2015.1094194

Martin, G. P., Currie, G., \& Finn, R. (2009). Leadership, Service Reform, and Public-Service Networks: The Case of Cancer-Genetics Pilots in the English NHS. Journal of Public Administration, Research and Theory, 19(7), 769-794. https://doi.org/10.1093/jopart/mun016

Mattison, O., \& Ramberg, U. (2015). Co-owned Local Government Organisations: Conditions for Strategy Development. Financial Accountability \& Management, 31(3), 0267-4424. https://doi.org/10.1111/faam.12057

Mattison, O., \& Thomasson, A. (2007). The strategic process and its impact on the outcome of a tender. Annals of Public and Cooperative Economics, 78(3), 439-454. https://doi.org/10.1111/j.1467-8292.2007.00341.x

Maxcy, B. (2009). New Public Management and District Reform; Managerialism and Deflection of Local Leadership in a Texas School District. Urban Education, 44(5), 489-521. https://doi.org/10.1177/0042085908318778

McDavid, J. C., \& Huse, I. (2012). Legislator Uses of Public Performance Reports: Findings From a Five-Year Study. American Journal of Evaluation, 33(1), 7-25. https://doi.org/10.1177/1098214011405311

Modell, S., \& Wiesel, F. (2008). Marketization and Performance Measurement in Swedish Central Government: A Comparative Institutionalist Study. ABACUS, 44(3), 251-283. https://doi.org/10.1111/j.1467-6281.2008.00262.x

Osborne, S. P., \& Gaebler, T. (1992). Reinventing government. Reading: Addison-Wesley. 
Park, S. M., \& Joaquin, M. E. (2012). Of alternating waves and shifting shores: the configuration of reform values in the US federal bureaucracy. International Review of Administrative Sciences, 78(3), 514-536. https://doi.org/10.1177/0020852312442659

Pawson, R. (2013). The science of evaluation: a realist manifesto. London: Sage. https://doi.org/10.4135/9781473913820

Petsoulas, C., Allen, P., Checkland, K., Coleman, A., Segar, J., Peckham, S., \& Mcdermott, I. (2014). Views of NHS commissioners on commissioning support provision. Evidence from a qualitative study examining the early development of clinical commissioning groups in England. BJM Open, 4(10), 1-9. https://doi.org/10.1136/bmjopen-2014-005970

Pettigrew, A. M., Woodman, R. W., \& Cameron, K. S. (2001). Studying organizational change and development: challenges for future research. The Academy of Management Journal, 44(4), 697-713. https://doi.org/10.2307/3069411

Pierre, J. (2013). Context, theory and rationality: an uneasy relationship? In C. Pollitt (Ed.), Context in Public Policy and Management; The Missing Link? (pp. 124-130). London: Edgar Elgar. https://doi.org/10.4337/9781781955147.00018

Pollitt, C. (2003). The essential public manager. Maidenhead: Open University Press.

Pollitt, C. (2013). Context: what kind of missing link? In C. Pollitt (Ed.), Context in Public Policy and Management: the Missing Link? (pp. 215-422). London: Edgar Elgar. https://doi.org/10.4337/9781781955147.00036

Pollitt, C., \& Bouckaert, G. (2017). Public Management Reform; a comparative analysis into the age of austerity (4 ed.). Oxford: Oxford University Press.

Pollitt, C., \& Dan, S. (2011). The Impacts of the New Public Management in Europe: A Meta-analysis. Deliverable 1.1. Retrieved from www.cocops.eu.

Pollitt, C., \& Dan, S. (2013). Searching for impacts in performance-oriented management reform; a review of the european literature. Public Performance and Management Review, 37(1), 7-32. https://doi.org/10.2753/PMR1530-9576370101

Robson, C. (2002). Real world research (2nd ed.). Malden: Blackwell Publishing.

Romney, A. K., Weller, S., \& Batchelder, W. (1986). Culture as consensus: A theory of culture and informant accuracy. American Anthropologist, 88, 313-338. https://doi.org/10.1525/aa.1986.88.2.02a00020

Sacranie, H. (2012). Hybridity Enacted in a Large English Housing Association: A Tale of Strategy, Culture and Community Investment. Housing Studies, 27(4), 533-552. https://doi.org/10.1080/02673037.2012.689691

Schmid, H., Dolev, T., \& Szabo, L. R. (2010). Community-based programs for children at risk: The case of budget flexibility in Departmens of Social Services in Israel. Children and Youth Services Review, 32(2), 178-184. https://doi.org/10.1016/j.childyouth.2009.08.006 
Schultz, L. T. (2015). The Ambivalent Relations Between Bureaucracy and Public Innovation: The Case of the Successful Failure Dial Police. International Journal of Public Administration, 38(2), 92-103. https://doi.org/10.1080/01900692.2014.930751

Scott, J. C. (1998). Seeing Like a State: How Certain Schemes to Improve the Human Condition have failed. New Heaven: Yale University Press.

Shin, J. C. (2010). Impacts of performance-based accountability on institutional performance in the U.S. Higher Education, 60(1), 47-68. https://doi.org/10.1007/s10734-009-9285-y

Shin, J. C., \& Jung, J. (2013). Academics job satisfaction and job stress across countries in the changing academic environments. Higher Education, 67(5), 603-620. https://doi.org/10.1007/s10734-013-9668-y

Shin, J. C., \& Jung, J. (2014). Academics job satisfaction and job stress across countries in the changing academic environments. Higher Education, 67, 603-620. https://doi.org/10.1007/s10734-013-9668-y

Shin, J. C., Kim, Y., Lim, H., Shim, B., \& Choi, Y. (2015). The 'sandwich generation' in Korean academe: between traditional academic authority and meritocratic culture. Studies in Higher Education, 40(8), 1406-1422. https://doi.org/10.1080/03075079.2015.1060710

Smith, M. J., Richards, D., Geddes, A., \& Mathers, H. (2011). Analysing policy delivery in the United Kingdom: The case of street crime and anti-social behaviour. Public Administration, 89(3), 975-1000. https://doi.org/10.1111/j.1467-9299.2010.01892.x

Sperber, D. (1996). Explaining culture; A naturalistic approach. Oxford: Blackwell Publishing.

Spillane, J. P., Brian, J. R., \& Reimer, T. (2002). Policy implementation and cognition: Reframing and refocusing implementation research. Review of Educational Research, 72(3), 387-431. https://doi.org/10.3102/00346543072003387

Steyvers, K., Reynart, H., \& Block, T. (2010). Team Work or Territorial War? Public Management Review, 12(1), 11-31. https://doi.org/10.1080/14719030902798297

Steyvers, K., Reynart, H., De Ceuninck, K., \& Valcke, T. (2006). Mayors in governance: Heading for efficiency and democracy? The Belgian case. Local Government Studies, 32(4), 429-445. https://doi.org/10.1080/03003930600792997

Sun, R., \& Van Ryzin, G. G. (2014). Are Performance Management Practices Associated With Better Outcomes? Empirical Evidence From Newy York Public Schools. American Review of Public Administration, 44(3), 324-338. https://doi.org/10.1177/0275074012468058

Svensson, J., Trommel, W., \& Lantink, T. (2008). Reemployment Services in the Netherlands: A Comparative Study of Bureacratic, Market, and Network Forms of Organization. Public Administration Review, 68(3), 505-515. https://doi.org/10.1111/j.1540-6210.2008.00886.x

Tashakkori, A., \& Teddlie, C. (Eds.). (2010). Mixed methods in social \& behavioral research (2nd ed.). Thousand Oaks: Sage Publications, Inc. https://doi.org/10.4135/9781506335193 


\section{Macrothink}

Journal of Public Administration and Governance ISSN 2161-7104 2018, Vol. 8, No. 1

Tummers, L. G., Bekkers, V., \& Steijn, B. (2009). Policy Alienation of Public Professionals. Public Management Review, 11(5), 685-706. https://doi.org/10.1080/14719030902798230

Tummers, L. G., Bekkers, V., \& Steijn, B. (2012). Policy Alienation of Public Professionals: A Comparative Case Study of Insurance Physicians and Secondary School Teachers. International Journal of Public Administration, 35(4), 259-271. https://doi.org/10.1080/01900692.2012.651413

Tummers, L. G., \& Den, D. L. (2013). The effects of work alienation on organisational commitment, work effort and work-to-family enrichment. Journal of Nursing Management, 21, 850-859. https://doi.org/10.1111/jonm.12159

Van der Voet, J., Groeneveld, S., \& Kuipers, B. S. (2014). Talking the Talk or Walking the Walk? The Leadership of Planned and Emergent Change in a Public Organization. Journal of Change Management, 14(2), 171-191. https://doi.org/10.1080/14697017.2013.805160

Verbeeten, F. H. M. (2008). Performance management practices in public sector organizations; Impact on performance. Accounting, Auditing \& Accountability Journal, 21(3), 427-454. https://doi.org/10.1108/09513570810863996

Verbeeten, F. H. M. (2011). Public sector cost management practices in The Netherlands. International Journal of Public Sector Management, 24(6), 492-506. https://doi.org/10.1108/09513551111163620

Verhoest, K. (2011). The Relevance of Culture in NPM. In T. Christensen \& P. Laegreid (Eds.), The Ashgate Research Companion to New Public Management. New York: Routledge.

Vigoda, G. E., Eldor, L., \& Schohat, L. M. (2012). Engage Them to Public Service: Conceptialization and Empirical Examination of Employee engagement in Public Administration. The American Review of Public Administration, 43(5), 518-538. https://doi.org/10.1177/0275074012450943

Virtanen, T. (2013). Context in the context - missing the missing links in the field of public administration. In C. Pollitt (Ed.), Context in Public Policy and Management: the Missing Link? (pp. 3-21). London: Edgar Elgar. https://doi.org/10.4337/9781781955147.00008

Weller, S. C., \& Baer, R. (2002). Measuring within- and between-group agreement: Identifying the proportion of shared and unique beliefs across samples. Field Methods, 14(1), 6-25. https://doi.org/10.1177/1525822X02014001002

Weller, S. C., \& Romney, A. K. (1988). Systematic data collection. Newbury Park: SAGE Publications. https://doi.org/10.4135/9781412986069

Wierenga, S. J., Kamsteeg, F. J., Simons, P. R., \& Veenswijk, M. (2013). Teachers making sense of result oriented teams; a cognitive anthropological approach of educational change. In press. 


\section{Macrothink}

Wihantoro, Y., Lowe, A., Cooper, S., \& Manochim, M. (2015). Bureaucratic reform in post-Asian Crisis Indonesia: The Directorate General of Tax. Critical Perspectives on Accounting, 31, 44-63. https://doi.org/10.1016/j.cpa.2015.04.002

Willem, A., \& Buelens, M. (2007). Knowledge Sharing in Public Sector Organizations: The Effect of Organizational Characteristics on Interdepartmental Knowledge Sharing. Journal of Public Administration, Research and Theory, 17(4), 581-606. https://doi.org/10.1093/jopart/mul021

Zafra, G. J. L., Rodriguez, B. M. P., \& Alcaide, M. L. (2012). Contrasting New Public Management (NPM) versus Post-NPM Through Financial Performance: A Cross-Sectional Analysis of Spanish Local Governments. Administration \& Society, 45(6), 710-747. https://doi.org/10.1177/0095399711433696

Zyoud, S. H., Al-Jabi, S. W., Sweileh, W. M., \& Awang, R. (2014). A Scopus-based examination of tobacco use publications in Middle Eastern Arab countries during the period 2003-2012. Harm Reduction Journal, 11(1), 1-9. https://doi.org/10.1186/1477-7517-11-14

\section{Copyright Disclaimer}

Copyright for this article is retained by the author(s), with first publication rights granted to the journal.

This is an open-access article distributed under the terms and conditions of the Creative Commons Attribution license (http://creativecommons.org/licenses/by/4.0/). 